\title{
Peace Education: Training for an Evolved Consciousness of Non-violence
}

\author{
Alev Yemenici \\ Çankaya University
}

\begin{abstract}
This paper aims to present a preliminary, brain-based model of peace education. In addition to subjects that current peace education models emphasize such as human rights education, environmental education and conflict resolution education, this model aims to introduce another level, namely the cellular level, at which neurobiological causes of violence and its early prevention can be addressed. Specifically, the model advocates dissemination of information on neurobiological causes and prevention of violence, and the impact of early trauma on the developing brain during the pre-natal, birth, and postnatal periods. These early periods are when a foundation of love chemicals or chemicals of violence is established and the fundamental brain architecture is laid down. In other words, through the education of children, adolescents, and adults, the model opens up a cellular dimension where violence can be prevented.
\end{abstract}

Keywords: Peace education, birth trauma, non-violence, brain enrichment, empowerment

\section{Introduction}

The current threat of global terrorism, ongoing conflicts, multi-faceted violence, and the highly disempowering conditions in which refugees worldwide have been forced to live make it necessary on the international and transnational levels to design new educational policies that revolve around peace education. Peace education as defined by Susan Fountain, a UNICEF consultant, "refers to the process of promoting the knowledge, skills, attitudes and values needed to bring about behavior changes that will enable children, youth and adults to prevent conflict and violence, both overt and structural; to resolve conflict peacefully; and to create the conditions conducive to peace, whether at an intrapersonal, interpersonal, intergroup, national, or international level."

Peace education ${ }^{2}$ is an overarching approach that not only teaches about different approaches to protecting and sustaining peace but also builds a common framework in which these approaches and strategies can be taught and practiced in the safety of classrooms. It provides knowledge and practices for people from all walks of life and children of any age group to establish lasting peace. It creates awareness regarding the dangers of violence,

Alev Yemenici, Assistant Professor, Department of Translation and Interpreting Studies, Çankaya University, Ankara, Turkey. Email: alevyemenici@cankaya.edu.tr.

Susan Fountain, "Peace Education in UNICEF" (working paper, UNICEF, June 1999), 1.

Ian M. Harris and Mary Lee Morrison, Peace Education (North Carolina: McFarland \& Company, Inc., Publishers, 2003), 16. 
warfare, and armed conflicts, terror, and misuse of power. It empowers learners to have a say in organizing national and international policies. It places human dignity and integrity at the core of educational policies.

To solve the current global conflicts and to build sustainable peace, acquisition and practice of cooperative/collaborative skills in negotiation and conflict management must begin at early stages of schooling. Skills, such as effective verbal/nonverbal communication, creative problem solving, critical thinking, self-awareness, and empathy in dealing with personal/relational and/or cultural conflicts can be effectively taught so that knowledge can be embodied through practice. Teaching how to identify and resolve/transform conflicts, how to recognize conflicting needs inherent in personal relations or in multicultural aspects of conflicts, and how to handle deep-seated cultural values in conflicts with an emphasis on negotiation strategies underlies the process of empowerment at the intrapersonal, interpersonal, social, national, and international levels.

Once this perspective finds its way into the formal and informal educational systems worldwide, a joint global movement regarding the quality and scope of education along the lines of peace education, the Joint Commission of World Education, can lay the foundation for global cooperation for conflict resolution and empowerment of the individual as a world citizen. Global cooperation with common goals has become a must if we desire to establish and sustain global peace by means of education.

The philosophy of peace education aims to teach "nonviolence, love, compassion and reverence for all life." 3 It brings to the forefront causes of violence and effective ways to deal with it. Peace education aims to examine issues related to peace and war, terrorism, dictatorial ideological oppression, military dominance, unethical political behavior as a way to preserve power, unjust systems, ethnic hatred, judicial system violation, vandalism, and different types of conflict. These factors, which have been regarded as the underlying causes of important global concerns, can be introduced within mainstream educational practices, with an emphasis on peace building. Peace building entails the study and practice of alternative non-violent conflict-resolution strategies, which center around core human values such as freedom of choice. Thus, when a common curriculum framework is jointly specified by the world's countries then a worldwide systematic peace-oriented education can emerge. Culture-specific adaptations of the curriculum would fulfill the nations' culture-specific needs, incorporating their unique socio-cultural characteristics and assets. In other words, a solid infrastructure to establish peace at a global level can be created as a result of joint effort.

Peace education provides for a curriculum in which students will learn and practice concepts, such as human rights, respect for rights, citizenship, democratic judicial systems, fairness, national and cross-cultural values and norms, constitution, multiculturalism, moral responsibility, diversity, freedom of choice, equality, and conflict management as integral parts of the curriculum. Students, depending on their grade level, learn to cherish the value of economic equity, understand the importance of equality of opportunity, internalize the essential nature of freedom, and virtually build and sustain international relations and democratic participation ${ }^{4}$ in an environment where appropriate strategies and practices are employed for different age groups.

\footnotetext{
Harris and Morrison, Peace Education, 9.

4 Betty Reardon, Educating for Human Dignity: Learning About Rights and Responsibilities (Philadelphia: University of 
Current peace education curricula consider the concept of non-violent communication, providing peace training to prevent violence and achieve sustainable peace by means of a variety of educational practices. These practices develop emotional intelligence along with cognitive intelligences, and create self-awareness with a focus on the role of human life and responsibility for all life forms on the planet. This paper aims to present an educational model ${ }^{5}$ that fosters a peace-oriented mind set, which needs for its establishment and sustenance an educational environment that enriches the brain, fully furnishing the individual with knowledge, skills, strategies, attitudes, and rewarding experiences to create internal, national, and international peace. Therefore, the present model proposes that peace education curricula should incorporate issues of brain development and the process of neurological imprinting. The model specifically focuses on the neurobiological aspect of peace and violence and takes into consideration the onset of human life: neurological imprints left in the brain of a fetus/ baby during gestation and/or after birth due to any kind of trauma.

This paper suggests that elimination of violence can be ensured if we incorporate into educational practices the knowledge of the fragility of the human brain in critical periods of its development, that is, the pre-natal, birth, and post-natal stages. Such knowledge and practices can empower people to a level where they can make informed choices in the face of high emotional valence. The proposed peace education model also claims that it is only when we assist the individual in the process of self-evaluation to willfully change his or her inner climate that the survival-oriented or primitive misuse of power can be eliminated. In this endeavour, the power of epigenetics will assist us in changing primitive survival programs. Such peace-oriented training needs to begin from the early stages of brain development, and should continue with lifelong training, which, for some, may require a professional coaching component that assists the individual during willful and conscious biological change at the cellular level from survival consciousness to an evolved consciousness of non-violence. At the core of this level of consciousness lies the deep understanding of the human dilemma, empathy for human suffering, desire for compassionate action, and reverence for all life. Only then can humanity enter the long-sought-for Age of Peace.

\section{Peace Education for the Whole Community}

To create such awareness and genuine desire for peace, the peace education model depicted here has targeted three major groups: children, adolescents, and adults (see Figure 1).

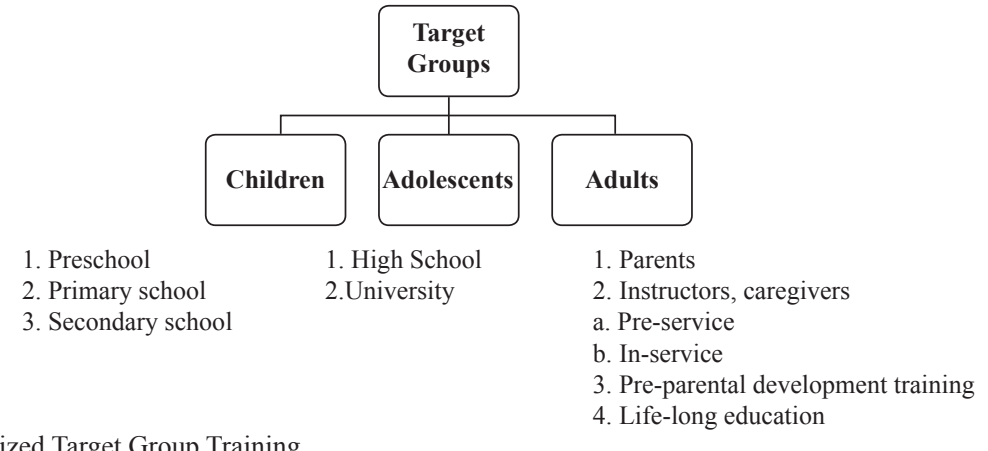

Figure 1: Specialized Target Group Training

5 This model in its preliminary stages was presented in a three-day workshop at Beit Berl College, Israel, February 2008, and at the WCCI, 13th World Conference in Education on "Creating a Global Culture of Peace: Strategies for Curriculum Development and Implementation" in Antalya, September 2008. The model presented at the WCCI was published in the proceedings for WCCI. 
From childhood onwards, human rights, human dignity, and integrity, ${ }^{6}$ along with core values of non-violent peace education, should be introduced into the overall school curriculum. Children benefit most when their brain is enriched with peaceful ideas and practices, when they are raised away from images and practices of domestic and structural violence. When children at early stages learn, understand, and internalize the meaning of rights violations in a safe school environment where there is no immediate threat to their well-being, they will be able to "develop empathy and solidarity with those whose rights have been denied." D During early childhood education, the development of social, emotional, and intellectual skills can be fostered through play, drama, art, and social games. Social games enable children to express their emotions in safely structured contexts during play instead of inhibiting them. In this way, children can embody their experience at the visceral level. When the basic concepts of human rights education, such as children's basic rights, are incorporated into the organized structure of dramatic play and social games, children begin to internalize the rules that regulate their social environment, accompanied by communication skills and constructive attitudes. They learn through experience what it feels like to take responsibility in society, to respect others' rights, to actively listen to friends and the teacher to be able to behave appropriately, observing rules and regulations. Thus, making non-violent peace education core curricula, with tasks and play that are accompanied by explicit instructions and re-emphasized at home, may eventually result in absence of all forms of violence and rights violations. Children will develop communication and negotiation skills to express their respect for rights and be able to assume responsible roles as sophisticated civilians who promote human rights. Then they will have the necessary scope and creative repertoire for non-violent alternatives that are greatly valued in a society of empowered individuals.

Education for peace provides for principles whose implementation empowers people to change the dysfunctional structures of societies by providing basic conflict transformation skills, such as attentive listening, peace-oriented communicative competence, reflection, selfassessment, creative problem solving, and mediation. Empowerment comes when people gain these essential "skills, attitudes and knowledge to create a safe world, maintain healthy bodies and build a sustainable environment." ${ }^{8}$ Doing so will enable children and adolescents to effectively put this knowledge into practical use to manage conflicts non-violently; to automatically choose peaceful ways in the face of conflict.

However, the philosophy of peace education advocates much more than teaching nonviolence. The concept of peace "implies human beings working together to resolve conflicts, respect standards of justice, satisfy basic needs, and honor human rights. Peace involves a respect for life and for the dignity of each human being without discrimination or prejudice." According to Reardon, peace education aims to transform the present human condition by "changing social structure[s] and patterns of thought that have created it." ${ }^{10}$ Children need to be enriched and sensitized with these core values at early stages of their development. When they gain a real understanding of the needs and desires that lie at the core of human experience, such as the need to be respected and loved, and the desire to experience achievement and acceptance, they may have all the resources they need to deal with conflicts

Harris and Morrison, Peace Education, 12.

10 Reardon, Educating for Human Dignity, 4. 
when they become adults, automatically tending towards peaceful solutions that benefit all sides. Although lifelong peace education is still key, such education in schools will help young people skillfully manage the higher needs in Maslow's hierarchy so that in the future our global village may benefit from the peaceful endeavors of political figures and leaders who have attained self-actualization.

Peace-oriented mind-sets help people transcend focusing on basic needs, which, in essence, prevent people from managing higher-order needs, such as emotional needs and self-actualization. Once people get used to fulfilling desires and deriving pleasure out of this fulfillment only, the mere act of satisfaction begins to captivate people. They may be obsessed with pursuing trivia, turning them into objects of attachment with an alluring quality.With higher goals come creativity and new paradigms. However, achieving this requires life-long learning and life-time commitment.

Adult training is also built into the instructional design of peace education. First and foremost, before people become parents they should be trained and sensitized towards the significant consequences of brain development during gestation. Whether the brain is enriched or deprived determines the quality of the individual's future life. Moreover, parents need to master non-violent ways to solve conflicts, and assist, support, and be role models for their children during their brain, behavior, and identity development throughout childhood and adolescence so that their children can choose peace in the face of life's challenges. Core values in the family or the larger society "can either contribute to or hinder behavior that promotes peace. The effectiveness of peace education is increased when strategies are used that address the value of the entire community." 11 Thus, not only school children but also adults need life-long non-violent peace education training to master fundamental peace concepts. Instructors who provide training and guidance with a peace-oriented frame of reference will lay the groundwork for citizens who respect cultural diversity and humanistic unity, who can establish harmonious relations between different religious and ethnic groups, who value freedom of expression and solidarity rather than competition, and who choose empowering attitudes rather than retaliation, cherishing harmony with nature.

If supported by healthy brain architecture and granted their human rights, peace education will give children, adolescents, and adults the skills and inner resources to choose a life of peace. And this infrastructure is laid down during pregnancy, and even before. ${ }^{12}$

\section{The Model}

The proposed model incorporates concepts from a variety of different areas to create a peace education model (See Fig. 2). First, the diverse areas that constitute the current model are briefly discussed. Then the model's four core issues of brain-based learning, life management skills, eliminating violence, and well-being in the pre-natal, birth, and post-natal periods are examined in detail. These issues are of crucial importance, as they mean life-long insurance for peace at the cellular level. Developing life skills to cope with stress, with a major focus on resilience training, contributes to an individual's cognitive and affective wellbeing. Eliminating violence towards women, especially during pregnancy and as mothers, is

\footnotetext{
11 Fountain, "Peace Education in UNICEF," 5.

12 Bruce Lipton, "Nature, Nurture, and the Power of Love: The Biology of Conscious Parenting," Youtube video, accessed September 6, 2015, http://www.youtube.com/watch?v=ScEN6ScMtZ8.
} 
essential when we consider the healthy development of a fetus' brain. Once enriched with empathy, loving care and kindness, the human brain is capable of emotionally intelligent coping when conflicts and threats arise. And finally, life-long brain-compatible education takes into consideration humans' holistic nature, with our multi-faceted cognitive, emotional, and self-actualizing needs and aspirations. In these ways, the individual is empowered to become autonomous and assume full responsibility for his or her actions in society, putting integrity above personal gains.

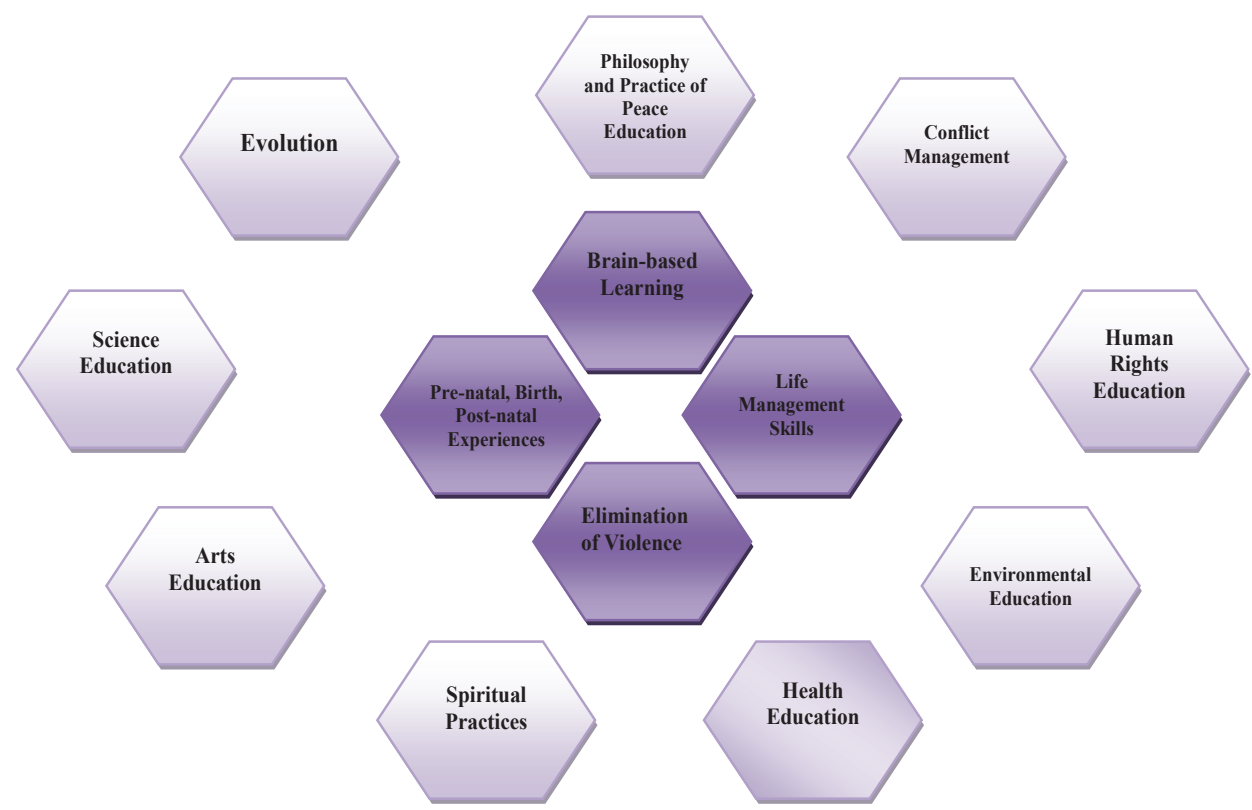

Figure 2: Components of the Model

\subsection{The outer components}

The outer circle of the model includes essential peace-education components, such as philosophy and practice of peace education, conflict management, human rights education, environmental education, all of which are commonly proposed by contemporary peace education specialists. The outer components also incorporate subjects common in general curricula, such as arts, science, (preventive) health education, as well as humanities and social sciences. All of these subjects should be dealt within a peace-oriented framework that advocates non-violence and human dignity. The infrastructure of such non-violence can only be laid when all subjects training is infused with the basic principle of "resolv[ing] disagreements without resorting to warfare or physical force, and for justice where human beings are treated with the dignity afforded them by their human rights." ${ }^{13}$ To do so, each subject should be tied to the main goals of peace education.

Education for peace distinguishes levels of peace, namely peacekeeping, peacemaking, and peacebuilding along with accompanying policies. These different definitions and perspectives on peace enable us to formulate concepts which would help us develop different

13 Harris and Morrison, Peace Education, 13. 
practices of conflict management and devise a variety of ways to deal with different types of violence.

With conflict management education more specific, non-violent strategies to deal with conflicts are introduced. Successful management of conflicts requires the skills of conflict resolution and conflict transformation at the intrapersonal, interpersonal, intergroup, national, and international levels. Conflict management education includes informing students about the psychological processes involved in personal/cultural conflicts, teaching them the social and psychological theories of conflict, as well as helping them to develop effective conflict resolution and social-emotional skills. Conflict management techniques assist learners in dealing with conflict situations effectively, which requires close investigation and understanding of factors causing misunderstandings, intolerance, and violence. Mastering constructive responses to conflict, however, necessitates development of non-violent communication/negotiation skills, mindful listening, compassionate communication, ${ }^{14}$ respect for individual differences, and empathy, as these skills inspire "understanding, sharing, helping, and cooperation." 15

Human rights education promotes the understanding and upholding of human rights and responsibilities regarding core values that revolve around resolving conflicts, i.e. social equity, cultural diversity, a commitment to democracy, justice for the whole community, and freedom. It familiarizes learners with the Universal Declaration of Human Rights, the role of the $\mathrm{UN}$ and the EU, the nongovernmental organizations and the contribution of these organizations to the human rights practices worldwide. It introduces concepts and language suitable to the learners' levels so that they understand how to exercise rights with accompanying social responsibilities. Such education sensitizes learners to human suffering due to injustice, political repression, and rights violations by incorporating arts, literature, drama, films and music. Learners become more adept at recognizing structural dominance and oppression, torture and persecution, by analyzing the conditions and reasons that bring about human suffering, the conditions that produce totalitarian systems, and the consequences of misuse of power.

Human rights education can be enriched through incorporating tranining that focuses on intercultural communicative competence since developing a healthy social identity to establish harmonious relationships is dependent on effective communication skills. Learning a variety of languages and cross-cultural communication skills along with rules that regulate cultural contexts sensitizes learners towards cultural and linguistic identities, cultural heritage, and diversity.

Health and environment education, on the other hand, raises awareness on general wellbeing of humans and other species. Health literacy provides information on addiction, stress, stress-related diseases, the relationship between stress and depression, preventive health care practices, introducing coping strategies for mental and physical health. Maintaining mind-body balance with such techniques enhances one's resilience, sense of grounding, and connectivity so that they can cope with difficulties, struggles, and challenges in life without losing overall quality of life and resorting to violence. Environmental education in schools

\footnotetext{
14 The author is in the process of developing a mindful communication approach that aims to develop an assertive, empowering, and mutually respectful communication strategy in personal and professional areas of interaction.

15 Sandra V. Sandy, "The Development of Conflict Resolution Skills," in The Handbook of Conflict Resolution: Theory and Practice, ed. Morton Deutsch, Peter T. Coleman, Eric C. Marcus. (San Francisco: Jossey-Bass, A Wiley Imprint, 2006 ), 366.
} 
aims at creating awareness regarding pollution, environmental damage, deterioration of ecosystems, and the interrelationship between human health and the environment. While dealing with major issues, such as global warming, climate change, species extinction, and environmental destruction on an intellectual level, learners also need to develop a naturalist intelligence while working on projects that require innovative ways to protect and preserve the quality of the environment

The peace education curricula should also include art, science, and humanities courses designed to promote non-violence and peace in the classroom. For example, the study of evolution can be instrumental in appreciating the bonds between humans and other species by revealing how life has changed through time. History of civilizations can help us understand the formation of cultures, religious doctrines, inventions, and cultural values. Understanding how these cultures evolved, the political systems and religions they adopted, and the ideas and inventions they cherished allow us to identify their influences on different cultures. The study of ancient myths sheds light on their role in the formation of the cultural values and belief systems of the past. Such a longitudinal perspective on life and culture can furnish learners with a desire to research and understand more, developing critical thinking skills in the process to decide which ideas to form, which perspective to take, and which path to follow with a non-violent frame of mind. Thus, studying religious doctrines and spiritual schools which influenced the formation, maintenance, and destruction of societies and cultures could prevent fanaticism, fundamentalism, fear, xenophobia, and terror, which are increasingly associated with religion. With such education, learners may develop an understanding as to the need to form belief systems and the underlying mechanisms of the human propensity to believe in the supernatural. Scientific analysis, synthesis, and evaluation of ideas and beliefs are necessary if we want to understand the diversity of cultural values and the psychology of belongingness.

With science and math education learners acquire the skills of reasoning, logic, hypothesizing, and forming theories with the ability to test them. They can monitor their own thought processes and witness those of others. Knowledge brings freedom of choice and empowerment. Thus, science training can take learners beyond the neurobiological survival program, helping them reconstruct the self and transcend the limits established by fear, ignorance, and hatred, which divide cultures and countries.

Arts education can be used as a healthy outlet for emotions and enable better communication. Art education creates a safe context in which authentic literature accompanied by visual and musical arts can be used for cultural enrichment, linguistic sophistication, and cognitive development. Art education activates the brain's often underused right hemisphere, which is responsible for intuition, emotional involvement, and creativity, balancing the logical and analytical left hemisphere's dominance. Thus, art education enhances creativity and prepares the individual for more artistic and holistic information processing. Art appreciation, on the other hand, brings the understanding of universal qualities that immortalize artwork, enhancing learners' creative perception and evaluation skills.

\subsection{The core of the model}

According to latest research, traumatic imprints at the early stages of life may result in a tendency towards violence. The mother's stressful or traumatic experiences, her mood, and 
whether she is undernourished during pregnancy have irreversible impacts on the brain of her baby. In other words, the fetus'/baby's experience of its mother's psychology in the womb or any repetitive experience of neglect or violence in early childhood has the power to shape the brain in such a way that the deprivation experienced may manifest itself as severe dissociation, leading to future acts of violence and/or a need to search for uncontrollable power. ${ }^{16}$ Thus, the individual may lose the capacity to emote and empathize with others, becoming self-centered and seeking instant gratification.

Violence that may dramatically change the architecture of the brain can be in many forms: verbal, emotional, physical, sexual, and military.Violence in the case of war, abuse of power in state affairs to subdue people, and exertion of control over personal/social freedom have detrimental effects on a larger scale. Once exposed to personal or social violence, the brain may choose to retaliate. The brain that is a product of early exposure to violence may be the cause of later institutional violence, which subdues civilians under oppressive economic conditions from the fear of losing institutional power. Such misuse of power leads to social or structural violence, which may create "circumstances that limit life, civil rights, health, personal freedom, and self-fulfilment." ${ }^{17}$ Brains motivated by power and ruled by fear create miserable health conditions, poor education, or high-quality education for only a select few, and deprive people of the freedom to live in humane conditions. It also manifests itself in the form of ecological violence. These different forms of violence may result from the fact that the neural connections in the brain of the individuals involved in feats of power and violent acts have been compromised. Those who fall short of devising peaceful and empowering governance policies and practices, and those who opt for destructive methods at national/ international levels, may not have had the chance to develop healthy neural connections under optimal non-violent conditions. Due to early trauma, their brains may not have evolved enough to control violent impulses and fear responses. Such self-centric survival-oriented impulses and behaviors arise from the terror center of the brain, due to imprints of traumatic and fearful experiences and/or deprivation, especially the early deprivation of love.

Thus, acquiring skills of non-violent communication gains momentum as the dissemination of knowledge strengthens and empowers the civic voice to balance power distribution in society when peace concepts start with early childhood education, when peace education continues during adolescence, and exists as an integral part of life-long education. This infrastructure requires pre-service and in-service peace education training for instructors and readily available materials for all age groups.

In peace education, knowing the causes of violence is crucial, creating awareness so that new prevention strategies can be developed. Asking the following questions may shed light on the very complex nature of violence: What are the internal and external causes that bring about violence? What is the role of the environment and the social structure in causing violence? How does the psychology of parents contribute to psychosocial risks, such as violence and harassment?

The peace education model proposed here, advocates that understanding the neurobiology of violence and love is crucial to answering the above questions. The answers to the following

${ }_{16}$ Arthur Janov, Imprints: The Lifelong Effects of the Birth Experience (New York: Coward-McCann, Inc., 1983); The Biology of Love (New York: Prometheus Books, 2000); The New Primal Scream (London: Abacus, 2003); Primal Healing (Franklin Lakes, N: J.: New Page Books, 2007).

${ }_{17}$ Harris and Morrison, Peace Education, 12. 
questions may create an awareness of major sources of violence in social structures so that aspects of society can reorganize themselves to control and eliminate the detrimental impacts of violence on children and adults. What brain chemicals are connected with violence? What is the relationship between the neurochemical imbalance that leads to violence and the pre-natal, birth, and post-natal periods? Under which circumstances does neurochemical imbalance occur? How does the brain develop under stress and trauma to cause violence? What is the role of deprivation and the impact of deprived environments in causing violence? What is the nature-nurture relationship in the formation of violent tendencies? What is the role of genetic pre-disposition? With a more holistic view on how the brain works, a more effective means for overcoming violence at the individual and even cellular level can be designed.

Using a brain-based approach to learning requires educators to explore, question, and interpret brain science that comes from many sources: brain imaging, animal research, brain diseases, brain trauma, and experiments on cognition and affect. This approach centers around constructing brain-enriching environments, investigating how the brain learns and opening up new territories for instructors to experience novelty while designing materials, devising methodologies, and evaluating performance. Brain-based learning brings to the forefront the devastating effects of stress, violence, and trauma on the brain and its relationship to identity development, helping teach others, such as educators and families, how to relieve and remove stress in schools and homes. Brain-based learning aims at enriching the brain with intrinsically motivating cognitive and affective learning, supported by transformational learning experiences.

When brain-friendly curricula are designed and implemented, multiple intelligences to enhance creativity and creative problem solution need to be taken into consideration. Emotional intelligence gains prominence when learners are trained to recognize both their own and others' emotions as they are required to appropriately respond in emotionally-laden situations. Students learn how to manage their emotions constructively and express themselves with effective communication strategies in challenging situations. Emotional intelligence incorporates non-violent brain-based pedagogy, fully equipping learners with non-violent communication strategies. Moreover, it focuses on personal learning styles and teaches a variety of study skills to enable learners to successfully complete tasks and assessments and to create a desire for life-long learning practices. It also aims to invoke curiosity and provides tools so that learners can acquire knowledge and skills on their own. Such autonomy emerges as learners conduct extensive research and experiments by drawing on resources with the guidance of the instructor, when they organize their thoughts effectively, express themselves well in writing, and defend their views and arguments skillfully when challenged.

The ever-accelerating speed of daily life, with its private and professional overload of duties and responsibilities, makes it essential to create balance so that the situation will not lead to debilitating stress and burnout. Developing resilience is tightly linked to effective stress-management and self-management skills, which can relieve anxiety, exhaustion, and aggression. When an individual is resilient enough to overcome obstacles to happiness, then the natural intrinsic reward system will become active, along with the neurochemical substrate that guides one's whole sense of well-being.

Brain-based learning prepares learners for a demanding world in which individual level conflicts may frequently turn into social conflicts and end up in violence. The present model 
advocates an individual level, brain-based intervention to address the root causes of such violence and either prevent individuals from harmful exposures or enhance their ability to overcome their fight or flight (survival) responses in highly stressful situations. One's levels of technology literacy, scientific thinking, field-related skills and qualifications, autonomy, self-discipline, awareness, emotional management, creative self-expression, team skills, stress management, communication skills and problem-solving abilities determine one's prospects in living, promoting a peaceful life. Brain-based learning aims to assist the learner in the construction of this peaceful self and develops many assets that contribute to a peaceful society.

In order to illustrate how peace and non-violence at the individual level can be achived by introducing brain-based learning, the following sections focus on critical stages of brain development, the effect of trauma, the neurochemistry of violence and love, and how this knowledge should be utilized at the core of peace education.

\subsubsection{Critical stages of brain development}

The brain of the fetus develops at an amazing speed during gestation. Hundreds of millions of brain cells, dendrites, and synaptic connections are formed every minute. During these precious moments, the emotional mood of the mother, her attitude towards life and the baby have a powerful effect on the brain. If, on the other hand, the mother experiences major challenges, is exposed to violence of any form, or if the fetus is undernourished, natural brain development may be impeded.

When a newborn is loved and when its needs are fulfilled, its internal serotonin- and oxytocin-based inhibitory system ${ }^{18}$ becomes well-established. The baby will thus feel at ease and relaxed. The frontal cortex, which is responsible for thinking, reflecting, and inhibiting sensations and impulses driven by the lower brain systems, such as the brain stem structures and the limbic system, will be enhanced. This enhancement will provide control in the later stages of life. In a healthy person, all the brain layers and hemispheres work in harmony.

When a traumatic experience occurs, however, this enhancement will not take place. In response to trauma, the brain protects itself by disconnecting some areas so that the input will not overwhelm the brain and information will not travel to and be interpreted by the left frontal cortex. An individual who has a weak frontal cortex due to early trauma will lack control and the individual will be hyperactive or prone to violence.

The strength of survival reactions to stress are caused by pre-natal threats in the womb, birth complications, after-birth experiences, lack of fulfillment of early needs, and emotional or life-threatening experiences later on in life. ${ }^{19}$ Lack of fulfillment of pre-natal or early needs results in a high concentration of stress hormones and leads to massive pain. Such pain requires an equally massive effort to hold it down. ${ }^{20}$ Combined with parental indifference or lack of love after birth, the pain will be compounded and not only impede the development of the frontal cortex and the limbic system but also damage the existing connections. Such treatment results in a variety of trauma-induced behaviors and thought patterns in the future, including obsessive-compulsive behavior patterns, paranoia, phobias, attention and concentration problems, and even health problems, as the impulse control mechanisms of the

\footnotetext{
18 Janov, Biology of Love.

19 Janov, Imprints; Biology of Love; Primal Scream; Primal Healing.

20 Janov, Biology of Love.
} 
neocortex may not develop well. This damage, i.e. traumatic-imprints, will result in chronic suffering throughout life.

According to Janov, there is a timetable of needs and critical periods for healthy brain development, and only when these needs are fulfilled can the brain develop to its potential. ${ }^{21}$ For instance, in the womb if the mother takes care of the baby by choosing a healthy lifestyle and a balanced diet without smoking, taking drugs or becoming unduly stressed, then the baby will develop the necessary neurochemicals to prepare it for high life performance and good health. The mother's love for the baby chemically transmitted in this way will well equip the baby for future life challenges. After the baby is born, its basic need for love is fulfilled if he or she is touched and cuddled. Touching is essential at the first stages of afterbirth development, especially when the baby is immediately brought to the mother for breastfeeding. ${ }^{22}$

Imprinting has three distinct stages, and each stage has a counterpart in brain development. ${ }^{23}$ Janov emphasizes that the first needs of a baby are the physical needs, such as nourishment and safety. In the second stage are emotional needs for love, understanding, and respect for feelings. The third stage includes intellectual needs, that is, needs of knowing and understanding. During these three stages, the most important ingredients are love and loverelated needs. All traumas are processed, coded, and stored at certain levels of consciousness, each of which has distinct memory systems and communication mechanisms. ${ }^{24}$ Baby's personality is determined in the womb from the third month onwards, as the primitive brain and nervous sytem register memories and imprints. ${ }^{25}$ During gestation and after birth, genuine love and interest in the baby and fulfilling its needs will determine how healthy the baby will be.Unless there is love and loving physical contact, the deprivation imprinted will be neurobiologically registered as trauma, with significant future consequences regarding the brain's natural development.

Janov states that early trauma creates great pain, which is repressed by the brain. The brain uses various feel-good neurochemicals, such as serotonin and endorphins to deal with trauma. Serotonin is an inhibitory neurotransmitter that mediates comfort, keeping imprinted impulses under control. However, if the trauma is too great and compounded, if there is great deprivation before, during, and/or just after birth, or if repression goes a long time without treatment, then the serotonin system may be damaged, resulting in hyperactive, fear-ridden, and impulsive children who have trouble learning. ${ }^{26}$

Another neurochemical agent of great importance is dopamine, which is an excitatory chemical that coordinates bodily movements and alerts the individual. Pre-natal stress changes the dopamine levels of the fetus. Early lack of love and touch depletes dopamine resources. ${ }^{27}$ A poor uterine environment and deprived family background or repression in the family also alters dopamine levels and may result in depression later. ${ }^{28}$

Extremely high dopamine levels can weaken the individual's gating system, while extremely low levels affect the integration capacity of the brain, resulting in a sense of

\footnotetext{
21 Janov, Biology of Love; Primal Scream.

22 Janov, Primal Scream.

23 Janov, Primal Scream.

Janov, Biology of Love; Primal Healing.

5 Janov, Biology of Love; Primal Scream.

26 Janov, Biology of Love.

27 Janov, Biology of Love.

28 Janov, Biology of Love.
} 
overwhelm and confusion even at low levels of stimuli. ${ }^{29}$ Increased dopamine in the right hemisphere lessens the ability to regulate emotions. Lower levels in the right hemisphere results in passivity; therefore, these individuals tend to give up on things easily. ${ }^{30}$ When dopamine levels are low in the left hemisphere, the person is prone to ideation, developing odd ideas to repress brain stem impulses. ${ }^{31}$

Research done by Teicher and colleagues reveals a strong link between children's physical, sexual, and emotional mistreatment and the development of psychiatric problems. ${ }^{32}$ This is because of the susceptibility of the brain during the critical formative years when it is being physically rewired by experience. The trauma experienced during these years reorganizes the nervous system. As the child lacks the resources necessary to process the experience, the impact of severe stress or abuse can leave an almost permanent imprint on its structure, modifying its functions. Abuse induces a cascade of neurobiological effects that irreversibly alter neural development. ${ }^{33}$ The psychobiological and neuroendocrinological effects of the trauma may result in a variety of abnormalities. ${ }^{34}$ Because of abnormalities developed in the brain, the individual continues to experience the trauma at the visceral level as if it were still going on. In later years, the child may be diagnosed with depression, anxiety, suicidal thoughts, post-traumatic stress disorder (PTSD), aggression, impulsiveness, delinquency, hyperactivity, and substance abuse. ${ }^{35}$

According to Teicher et al., ${ }^{36}$ childhood abuse disrupts the healthy maturation of the limbic structures and stimulates the amygdala into a state of heightened electrical irritability. Early abuse damages the hippocampus through exposure to stress hormones in its critical developmental phases. The reduction of the left amygdala correlates with feelings of depression and irritability or hostility. ${ }^{37}$ In addition, early stress reconfigures the molecular organization of the limbic regions: it alters the GABA receptors in the amygdala. Furthermore, middle parts of the corpus callosum, the neural bridge that connects the two hemispheres of the brain, were found significantly smaller in boys and girls exposed to abuse.

According to other studies, the left hippocampus of abused patients with PTSD was $12 \%$ smaller than those of the healthy controls. ${ }^{38}$ Bremner et al. found a significant correlation between short-term verbal memory deficits and smaller right hippocampal volume in patients with PTSD. ${ }^{39}$ According to the researchers, the impact of trauma on hippocampal regions may be dependent on the time when the trauma was experienced. Early trauma appears to cause cell shrinkage. Neuronal plasticity in the young brain means that short-term memory functions normally mediated by the hippocampus may be partially taken over by other brain regions; however, since the brain loses plasticity with age, trauma experienced later in life may lead to the loss of memory functions.

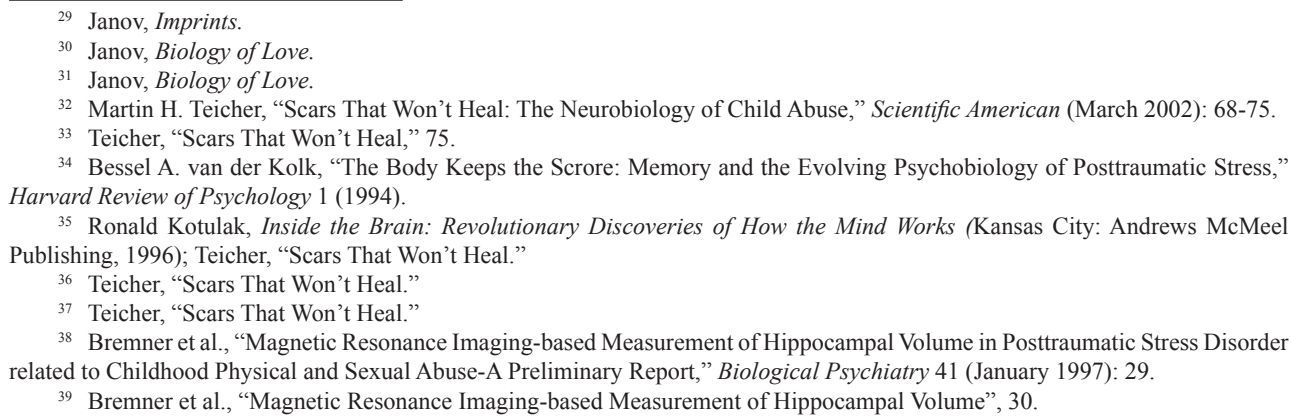

32 Martin H. Teicher, "Scars That Won't Heal: The Neurobiology of Child Abuse," Scientific American (March 2002): 68-75.

33 Teicher, "Scars That Won't Heal," 75.

${ }^{34}$ Bessel A. van der Kolk, "The Body Keeps the Scrore: Memory and the Evolving Psychobiology of Posttraumatic Stress," Harvard Review of Psychology 1 (1994).

35 Ronald Kotulak, Inside the Brain: Revolutionary Discoveries of How the Mind Works (Kansas City: Andrews McMeel Publishing, 1996); Teicher, "Scars That Won't Heal."

36 Teicher, "Scars That Won't Heal."

37 Teicher, "Scars That Won't Heal."

38 Bremner et al., "Magnetic Resonance Imaging-based Measurement of Hippocampal Volume in Posttraumatic Stress Disorder related to Childhood Physical and Sexual Abuse-A Preliminary Report," Biological Psychiatry 41 (January 1997$): 29$.

39 Bremner et al., "Magnetic Resonance Imaging-based Measurement of Hippocampal Volume", 30. 
Teicher et al ${ }^{40}$ found clinically significant brain-wave abnormalities and EEG anomalies in patients who had experienced serious physical and sexual abuse; the EEG anomalies apparently indicate limbic irritability.

In strong support of the previous research ${ }^{41}$ Teicher et al. reiterate the importance of the absence of stress in human development:

We hypothesize that adequate nurturing and the absence of intense early stress permits our brains to develop in a manner that is less aggressive and more emotionally stable, social, empathic, and hemispherically integrated. We believe that this process enhances the ability of social animals to build more complex interpersonal structures and enables humans to better realize their creative potential. ${ }^{42}$

\subsubsection{Violence and its causes}

Having emphasized the significance of early love for the fetus/baby, we will now focus on the detrimental consequences of deprivation of love and how it leads to violence. As noted above, sensory deprivation, deprivation of love, and exposure to violence are detrimental early experiences that permanently change the physical structure of the brain. ${ }^{43}$ These changes may result in physical and mental diseases and/or emotional and psychological imbalances, establishing impulsive thought processes that make an individual view violence as an acceptable way of dealing with problems. ${ }^{44}$

If there are extreme levels of stress hormones present during pregnancy, the fetus brain adapts itself to the stressful conditions that convey survival and threat messages to the fetus through the mother's perception of the world. ${ }^{45}$ Thus, "exposure to early stress generates molecular and neurobiological effects that alter neural development in an adaptive way that prepares the adult brain to survive and reproduce in a dangerous world." 46

Early stress generally means domestic violence. Once the brain realizes that it is under threat at home, serotonin and noradrenaline imbalances may occur. Especially when the child is genetically vulnerable to stress, the wiring of the brain and the distribution of neurohormones lay the groundwork for violence for the rest of the individual's lifetime. Deprivation of love in the family, domestic violence, poverty, shattered families, and drug abuse can rewire the brain in such a way that neurohormones prepare the body for aggression. ${ }^{47}$ According to Kotulak, the most susceptible children to violence "have low IQs, poor school attainment, high impulsivity, and lack of concentration. They tend to come from big families, lowincome families, and have parents who were convicted of a crime; they grow up with harsh discipline, poor supervision, and separation from parents. ${ }^{~} 48$

Aggression, when balanced, is a universal positive force that enables humans to stand up for their rights to live, seeking and cherishing food and shelter. "Normal aggression has a set point, like body temperature, which is regulated by brain chemicals. Most people are born with a balance of these neurochemicals. ${ }^{" 49}$ Depending on the amount and distribution of

\footnotetext{
40 Teicher, "Scars That Won't Heal," 71.

41 Janov, Imprints; Biology of Love; Primal Scream.

42 Teicher, "Scars That Won't Heal," 75.

43 Janov, Imprints; Biology of Love; Primal Scream.

44 Kotulak, Inside the Brain.

45 Lipton, "Conscious Parenting".

46 Teicher, "Scars That Won't Heal," 75.

47 Kotulak, Inside the Brain.

48 Kotulak, Inside the Brain, 69.

49 Kotulak, Inside the Brain, 67.
} 
these chemicals, however, aggression may increase or decrease. Similarly, fear, in essence, helps animals and humans avoid danger. Thus, it has a survival value. However, an extremely fearful experience such as a trauma can imprint an emotional memory, causing physical changes in the brain architecture and resulting in permanent behavioral changes. Thus, "fear plays an important role in psychopathology. While fear is an adaptive component of [the] response to potentially threatening stimuli, too much or inappropriate fear accounts for many common psychiatric problems." 50

Fear is processed and memorized by a set of circuits that detect and respond to danger. The link between a scary stimulus and the reaction is laid down as a special, primal kind of memory, which is distinct from the explicit or rational memory that forms after the experience. ${ }^{51}$ Emotional content of the memory is formed in the amygdala. ${ }^{52}$ Usually, the memories encoded here last a lifetime because the plasticity in the lateral amygdala may serve to permanently store the fear-based association. ${ }^{53}$ Since the brain tends to store highvalence memories permanently, fear memories short-circuit rational thought, block normal behavior, and disturb normal thought patterns. In some people with anxiety disorders, emotional memory seems to override logic. When activated by a similar stimulus, primal memory tends to override rational memory so that the fear response escalates into paralyzing anxiety. ${ }^{54}$ For instance, in people afraid of snakes, the sight of a stick or a rope can trigger a paralyzing terror.

A healthy amygdala can filter out unthreatening stimuli. Without this filtering, we would respond to all kinds of inappropriate fear cues. However, if the amygdala lets too much information in, even mildly scary stimuli can be terrifying and override rational thought. Once primed by one or more frightening experiences, a person with a 'leaky' amygdala may become hypervigilant.

When our neurochemicals are balanced, we are able to rationally react to the events in our external reality. Serotonin, as a mood regulator, controls primitive drives and emotions, such as the drive for sex and appetite at normal levels. It also controls aggression, sleep, suicidal tendencies, arousal, and pain. According to Dr. Michael Raleigh, normal serotonin levels are associated with clear thinking and social success. ${ }^{55}$ With the right amounts, the brain masters all of its resources to make use of the opportunities in its environment, balancing the risks against the benefits. In such individuals, enough aggression is allowed to surface so that they can be assertive and get things done. ${ }^{56}$

An imbalance of serotonin seems to change the brain's perception of fear, especially if the imbalance happens in infancy. One study ${ }^{57}$ found that depriving infant mice of some of their serotonin made them anxious as adults. There is evidence that serotonin must be available to the brain in adequate amounts in early childhood to protect it from anxiety. ${ }^{58}$

When serotonin declines in the brain, as is often the case with abused children or with

\footnotetext{
${ }^{50}$ Marie A. Pezze and Joram Feldon, "Mesolimbic Dopaminergic Pathways in Fear Conditioning," Progress in Neurobiology 74 (December 2004): 1.

51 Janov, Imprints.

52 Joseph LeDoux, The Emotional Brain (New York: Simon \& Schuster, 1998).

53 Teicher, "Scars That Won't Heal."

54 Janov, Imprints; Biology of Love.

55 Kotulak, Inside the Brain.

56 Kotulak, Inside the Brain.

57 Cornelius Gross, et al., "Serotonin 1A Receptor Acts During Development to Establish Normal Anxiety-like Behavior in the Adult," Nature 416 (2002): 396-400.

58 Gross et al., "Serotonin 1A Receptor."
} 
alcohol and drug abuse, impulsive aggression is unleashed. With serotonin depletion a person may also start to lose interest in life and signs of happiness decrease; depression and a tendency to suicide steps in. With depletion comes a lack of control, irritability, loss of temper, and explosive rage.

Other neurochemicals also play an important role in aggression. Dopamine is another neurotransmitter which most potently modulates humans' motivational and pleasure-related behaviors as well as the mechanisms underlying states of fear and anxiety. There is strong evidence for the important role of the stress-responsive mesolimbic dopaminergic system in controlling mood. ${ }^{59}$ When dopamine levels drop substantially, a person may use violence or hallucinogenic drugs to activate the pleasure pathways in the brain. ${ }^{60}$

Noradrenaline is a neurochemical that notifies the body when it is under stress or threat. It alerts the brain's survival mechanism to take immediate action in response to danger, reorganizing the distribution and amount of neurohormones, such as adrenaline and other chemicals. Noradrenaline may be instrumental in both hot-blooded and cold-blooded violence; when noradrenaline is high, impulsive violence becomes more likely, ${ }^{61}$ and as low levels cause under-arousal, the cold-blooded violence of a serial killer may be more likely. ${ }^{62}$ Thus, behind aggression, violence, or criminal activity, a combination of serotonin and noradrenaline may be at work. When high noradrenaline was superimposed on low serotonin, impulsive aggression was aimed at others. When low noradrenaline was combined with low serotonin, aggression was aimed inward ${ }^{63}$ According to research, ${ }^{64}$ impulsive aggression may also be caused by dysfunctional serotonin-dopamine interactions. Different combinations of these neurochemicals as triggered by conditions and experiences may produce different violent consequences.

Genetic heritage may also make people susceptible to low serotonin. If a child is exposed to violence at home, such experience appears to determine how that gene will be expressed. Research has just begun to unveil the power of the outer environment in gene expression: epigenetics. According to Lipton, ${ }^{65}$ the environment's signals are received by cell membranes, which activate effector proteins within the cell. As a result, new genes are formed: "Integral membrane receptor-effector proteins are the fundamental physical subunits of the cellular brain's 'intelligence' mechanism. By functional definition, these protein complexes are 'perception switches' that link reception of environmental stimuli to response-generating protein pathways." 966

This piece of information has many valuable implications. First and foremost, if an expectant mother has a stressful life, then the way she perceives the world will trigger the expression of genes that will prepare the baby for a stressful life. In other words, the baby will be equipped with more stress chemicals to be able to survive in an insecure world. Second, the

\footnotetext{
59 Christiane M. Thiel and Rainer K. W. Schwarting, "Dopaminergic Lateralization in the Forebrain: Relations to Behavior Asymmetries and Anxiety in Male Wistar Rats," Neuropsychobiology 43 (2001): 192-99.

${ }^{60}$ Michael A. Bozarth, "Pleasure Systems in the Brain," in Pleasure: The Politics and the Reality, ed. David M. Warburton (New York: John Wiley \& Sons, 1994).

61 Kotulak, Inside the Brain.

62 Kotulak, Inside the Brain.

63 Kotulak, Inside the Brain.

${ }^{64}$ Dongju Seo, Christopher J. Patrick, and Patrick J. Kennealy, "Role of Serotonin and Dopamine System Interactions in the Neurobiology of Impulsive Aggression and its Comorbidity with other Clinical Disorders," Aggressive Violent Behaviour 13 (2008): 383-95.

65 Lipton, "Conscious Parenting"; The Biology of Belief (Santa Rosa: Mountain of Love/Elite Books, 2005).

${ }^{66}$ Lipton, Biology of Belief, 128.
} 
brain will shape itself in such a way that the neurochemicals and the structures that evolve for survival will rise to prominence. This is exemplified in Keverne's ${ }^{67}$ research, which reveals a genetic mechanism through which regulatory genes inherited from the mother promote the expansion of the neocortex, which is a more-evolved part of the brain. Genes inherited from the father support the brain stem, which promote a bigger body and survival skills. In other words, the organism decides which gene to silence and which part of the brain to develop based on the parents' perceptions and experiences.

Thus, based on these research studies, it would not be wrong to claim that stress and threat in the environment will trigger mechanisms that affect the DNA so that the brain can adapt itself to its environment. When we consider the fact that the human organism is genetically pre-programmed for survival, if children at early stages are exposed to fear-inducing violent events and circumstances, their brain will change to accommodate future behavior that will orient them towards destruction and violence. They will have limited ability to empathize with others; because empathy is a function of the prefrontal regions that need experiences of love and compassion to develop. If there is threat in the environment, brain structures and neurochemistry will tend towards developing for survival; if there is a loving and caring environment, then brain structures and neurochemistry will tend towards developing for cognitive sophistication and creative, non-violent self expression.

\subsubsection{Love and elimination of violence}

Having covered the multi-faceted causes of violence and the effects of violence on the brain, we will now look at the neurobiological aspects of love, which can counteract its effects. If we really want to establish global societies based on peace and raise new generations that look into peaceful solutions to conflicts, we need to eliminate stress, resolve uncontrollable violent impulses that are closely connected to the experience of threat and violence in the family, and lay the groundwork for a more peaceful brain and more peaceful societies. For this reason, we need to encourage the secretion of love chemicals and support the development of brain structures that mediate the experience of love through loving, caring and empowering environments beginning from pregnancy onwards.

Love (both romantic and maternal) occupies a unique area in the brain's specific regions, each of which may overlap or differentiate. These regions ${ }^{68}$ belong to the brain's reward system, which contains a high density of receptors for oxytocin and vasopressin. When these regions are activated, regions that process negative emotions, mentalizing, social judgment, and critical social assessment are deactivated.

Activation of the brain's reward systems can be considered a normal component of behavior. These regions govern an organism's approach to goals that are normally beneficial and promote survival ${ }^{69}$ by using neurochemicals such as dopamine, which gives us the feeling of satisfaction, and oxytocin, which produces feelings of love.

Oxytocin (and vasopressin) is also involved in maternal attachment and adult pairbonding; they may even play a role in memory and learning. During breastfeeding or sucking, maternal oxytocin levels increase. Oxytocin may also be released by touch and warmth, thus

\footnotetext{
${ }^{67}$ E. Barry Keverne, "Genomic Imprinting, Maternal Care, and Brain Evolution,” Hormones and Behavior 40 (2001): 146-55.

68 Andreas Bartels and Semir Zeki, "The Neural Basis of Romantic Love," NeuroReport 11 (2000): 3829-34; Andreas Bartels and Semir Zeki, "The Neural Correlates of Maternal and Romantic Love," NeuroImage 21 (2004): 1155-66.

69 Bozarth, "Pleasure Systems."
} 
it may play a role in positive social interactions and emotions. Oxytocin specifically has an anti-stress effect. ${ }^{70}$

According to Uvnas-Moberg, "oxytocin coordinates both the causes and effects of social interactions. During social interactions, oxytocin can be released by sensory stimuli perceived as positive, including touch, warmth and odors." " Oxytocin is also associated with a decrease in heart rate, blood pressure, and cortisol levels, thus reducing the deleterious effects of chronic stress. In other words, loving and supportive interactions support the body's natural tendency towards repair, growth, and bonding.

When the significance of the pre-natal environment and/or the first months of life are taken into consideration, the power of love chemicals in shaping the brain is evident. According to Janov, if the brain of the fetus/baby does not fully develop due to pre-natal experiences, imprints such as "I'm not loved"and/or "I'm not worthy" will be laid down almost permanently. ${ }^{72}$ To compound the problem, because lack of love hinders connections between the three levels of the brain and because the lack of fully-formed connections prevents the individual from becoming consciously aware of his or her feelings, ${ }^{73}$ people usually need intense professional assistance to change them.

Adequate love, compassion, and understanding, however, enable a baby to have a reward system that is naturally activated by daily life experiences. When a person encounters stress or compounded challenges in daily life, the brain connections and neurochemical distributions laid down by love experienced pre- and post-natally, will allow him or her utilize inner resources to resolve them. However, if rewards normally effective in influencing behavior lose their ability to motivate, or if natural rewards do not activate the reward system very strongly, the individual may turn towards drugs or delinquent behavior to get the same feelings. ${ }^{74}$

\section{Conclusion}

As evident from the discussion of the mechanisms of violence and love, there is another level to peace education, namely, the cellular level. Enriched with the knowledge of the neurobiology of violence and love, peace education can develop effective ways to eliminate the root causes of violence. Understanding how the brain physically changes, how it loses its neural affluence when exposed to violence or how neural networks thrive when stimulated in enriched environments can aid the education specialists in designing new educational policies to prevent cognitive and affective impairment due to environmental deprivation and neglect. In this way, solutions to global concerns can be addressed at the most fundamental levels.

Specifically, the proposed model advocates disseminating information on the effects of violence, fear, stress, and trauma during the pre-natal, birth, and post-natal periods when the foundation of love chemicals or chemicals of violence are established and the brain architecture is formed. In other words, through educating parents, children, and teachers, including pre-parental development training, the model opens up a cellular dimension where violence can be prevented before its pre-natal foundation is established. This cellular

${ }^{70}$ Kerstin Uvnas-Moberg, "Oxytocin May Mediate the Benefits of Positive Social Interaction and Emotions," Psychoneuroendocrinology 23 (1998): 819-35.

71 Uvnas-Moberg, “Oxytocin,” 820.

72 Janov, Biology of Love.

73 Janov, Biology of Love.

74 Janov, Imprints; Biology of Love; Primal Scream. 
dimension may act as a neurobiological foundation on which a more loving and caring generation of human beings who can choose peaceful alternatives to violence and who can provide critical evaluation of alternative strategies can be raised. To ensure this result, national curricula should be redesigned based on the framework set by the peace education paradigm, incorporating courses from disciplines that cultivate creativity, peaceful solutions to global concerns, and critical mind-sets. However, betterment of education systems on a global scale is dependent upon cooperation in the form of a Joint Commission of World Education.

Since individuals who are raised in loving and empowering environments develop more evolved brains that grant them a compassionate outlook on life, peace education has the potential to transform today's world into one where peace consciousness resides.Peace consciousness is raised by acquiring knowledge about non-violent negotiation, reconciliation strategies that can be used during major conflicts and crises, and major causes of violence. When students cultivate means and strategies for non-violent struggle, realize the importance of absolute replacement of armed struggle and wars with non-violent peaceful negotiations by providing critical evaluation of alternative strategies, they will be able to appreciate nonviolent resolution of national and international conflicts. They will perceive alternatives to violence, displaying reverence for all life forms, human rights, and our planet. Education to awaken the power to eliminate violence and terror from the world stage through nonviolence is an evolved act of compassion that requires a high intellectual capacity. Taking compassionate action can transform the images of cultural violence engraved in the minds of today's youth by "the media, entertainment industry, politics, national and foreign policy, community and the family." 75 Active non-violence can be regarded as positive peace, which emphasizes the value of cooperation to resolve conflicts by respecting "standards of justice, satisfying basic needs, and honoring human rights" as "peace involves a respect for life and for the dignity of each human being without discrimination or prejudice." 76 Learning about non-violent solutions, children will become functional citizens who can solve conflicts peacefully and non-violently, and who can thus end intolerance, discrimination, and social injustice. However, to actualize this, one needs to achieve peace at the cellular level.

In our century, the world cannot take the risk of building leaders who have irritable, hostile, and overactive amygdala due to traumatic experiences or early deprivation. Such individuals are doomed to tyrannize their own countries and threaten the welfare of others especially if they have low levels of dopamine, serotonin, and unbalanced levels of noradrenaline.

Our DNA is pre-programmed to struggle for survival. As such, in the evolutionary process, the human race has become extremely skilled in survival. Once a physical struggle, survival is now a mental game of the highest quality, with technology and knowledge in the service of highly intelligent power sources that control the planet. This means that our genetic survival programming and control mechanisms have evolved into very sophisticated tools to ensure survival and control at all costs. This act of survival consciousness accompanied by the desire to exert power to control humanity with ingenious political or military strategies and moves may assume the role of relentless terror, wars, invasions, the use of the state of the art arms and technologies to control disempowered masses. If we genuinely desire to bring peace to our planet, we must induce our own biological mutation, taking our cells away from the primitive level of survival programming into an evolved state of consciousness: the

\footnotetext{
Harris, Peace Education, 10.

76 Harris, Peace Education, 12.
} 
consciousness of love, compassion, and peace. In other words, we can start to change from the inside out by using the power of knowledge. Education, from this perspective, is the first step. Policy makers must drop armed survival strategies and display their genuine concern for the well-being of our species and our planet. Thus, education turns into a symbolic catalyst that can assist the individual and societies to consciously and willfully change their genetic encodings. This mutation is a must if we desire to become an empowered species with peace inside, peace outside, and peace in action with compassion.

\section{Bibliography}

Bartels, Andreas, and Semir Zeki. “The Neural Basis of Romantic Love.” NeuroReport 11, no.17 (2000): 3829-834.

_ . "The Neural Correlates of Maternal and Romantic Love." NeuroImage 21 (2003): 1155-166.

Bozarth, Michael, A. "Pleasure Systems in the Brain.” In Pleasure: The Politics and the Reality, edited by David M. Warburton, 5-14. New York: John Wiley \& Sons, 1994.

Bremner, J. Douglas, Penny Randall, Eric Vermetten, Lawrence Staib, Richard A. Bronen, Carolyn Mazure, Sandi Capelli, Gregory McCarthy, Robert B. Innis, and Dennis S. Charney. "Magnetic Resonance Imaging-based Measurement of Hippocampal Volume in Posttraumatic Stress Disorder related to Childhood Physical and Sexual Abuse-A Preliminary Report.” Biological Psychiatry 41 (January 1997): 23-32.

Fountain, Susan. "Peace Education in UNICEF." Working paper, UNICEF, June 1999.

Gross, Cornelius, Xiaoxi Zhuang, Kimberley Stark, Sylvie Ramboz, Ronald Oosting, Lynn Kirby, Luca Santarelli, Sheryl Beck, and René Hen. "Serotonin 1A Receptor Acts During Development to Establish Normal Anxietylike Behavior in the Adult." Nature 416 (2002): 396-400.

Harris, Ian M., and Mary Lee Morrison. Peace Education. North Carolina: McFarland \& Company, Inc., Publishers, 2003.

Janov, Arthur. The Biology of Love. New York: Prometheus Books, 2000.

- Imprints: The Lifelong Effects of the Birth Experience. New York: Coward-McCann, Inc., 1983.

- The New Primal Scream. London: Abacus, 2003.

—. Primal Healing. Franklin Lakes, N: J.: New Page Books, 2007.

Keverne, E. Barry. “Genomic Imprinting, Maternal Care, and Brain Evolution.” Hormones and Behavior 40 (2001): $146-55$.

van der Kolk, Bessel A. "The Body Keeps the Scrore: Memory and the Evolving Psychobiology of Posttraumatic Stress." Harvard Review of Psychology 1, no. 5 (1994): 253-65.

Kotulak, Ronald. Inside the Brain: Revolutionary Discoveries of How the Mind Works. Kansas City: Andrews McMeel Publishing, 1996.

LeDoux, Joseph. The Emotional Brain. New York: Simon \& Schuster, 1998.

Lipton, Bruce. The Biology of Belief. Santa Rosa: Mountain of Love/Elite Books, 2005.

Pezze, Marie A., and Joram Feldon. "Mesolimbic Dopaminergic Pathways in Fear Conditioning." Progress in Neurobiology 74 (December 2004): 301-20.

Reardon, Betty. Educating for Human Dignity: Learning about Rights and Responsibilities. Philadelphia: University of Pennsylvania Press, 1995.

Sandy, Sandra V. "The Development of Conflict Resolution Skills.” In The Handbook of Conflict Resolution: Theory and Practice, edited by Morton Deutsch, Peter T. Coleman, Eric C. Marcus, 356-388. San Francisco: JosseyBass, A Wiley Imprint, 2006.

Seo, Dongju, Christopher J. Patrick, and Patrick J. Kennealy. "Role of Serotonin and Dopamine System Interactions in the Neurobiology of Impulsive Aggression and its Comorbidity with other Clinical Disorders." Aggressive Violent Behaviour 13 (2008): 383-95. 
Teicher, Martin H. "Scars That Won't Heal: The Neurobiology of Child Abuse.” Scientific American (March 2002): 68-75.

Thiel, Christiane M., and Rainer K. W. Schwarting. "Dopaminergic Lateralization in the Forebrain: Relations to Behavior Asymmetries and Anxiety in Male Wistar Rats.” Neuropsychobiology 43 (2001): 192-99.

Uvnas-Moberg, Kerstin. "Oxytocin May Mediate the Benefits of Positive Social Interaction and Emotions." Psychoneuroendocrinology 23, no. 8 (1998): 819-35. 